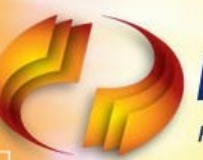

\section{AVALIAÇÃO DA EFICIÊNCIA ENERGÉTICA EM EDIFICAÇÕES E SUA RELAÇÃO COM OS MATERIAIS CONSTRUTIVOS EMPREGADOS}

\section{EVALUATION OF ENERGY EFFICIENCY IN BUILDINGS AND THEIR RELATIONSHIP WITH THEIR BUILDING MATERIALS}

\author{
Carine Cristiane Machado Urbim Pasa*E-mail: carineurbim@yahoo.com.br \\ Leandro Antonio Pasa** E-mail: pasa@utfpr.edu.br \\ Aldo Braghini Junior*E-mail: aldo@utfpr.edu.br \\ Samuel Nelson Melegari de Souza *** E-mail: samuel.souza@unioeste.br \\ * Universidade Tecnológica Federal do Paraná - UTFPR, Ponta Grossa, PR \\ ** Universidade Tecnológica Federal do Paraná - UTFPR, Medianeira, PR \\ *** Universidade Estadual do Oeste do Paraná - UNIOESTE, Cascavel, PR
}

\begin{abstract}
Resumo: Este trabalho baseou-se em pesquisa anterior de Pasa e Braghini (2010), onde se avaliou a eficiência energética de edificações unifamiliares para as capitais da região Sul do Brasil. Desta vez, optou-se por tomar a residência que apresentou melhor eficiência como padrão e fazer o teste com quatro configurações diferentes de materiais construtivos. Utilizou-se o método Graus-Dia para a simulação da quantidade de energia requerida para resfriamento e aquecimento na residência, para cada uma das configurações, para a cidade de Curitiba. Pode-se observar que o material construtivo adotado influenciou no resultado final.
\end{abstract}

Palavras - chave: Conforto térmico. Graus-dia. Eficiência energética. Consumo energético. Materiais construtivos.

Abstract: This work was based on earlier research of Pasa and Braghini (2010), which evaluated the energy efficiency of single-family buildings for the capital of southern Brazil. This time we decided to take residence which shows better performance as standard and do the test with four different configurations of building materials. We used the degree-day method to simulate the amount of energy required for cooling and heating in the residence for each of the settings for the city of Curitiba. We can observe that the adopted construction material influenced the final result.

Keywords: Thermal comfort. Degree days. Energy efficiency. Energy. Construction materials.

\section{INTRODUÇÃO}

A busca por conforto já consome grande parte da demanda de energia elétrica residencial. Os projetos atuais fazem uso em grande escala dos aparelhos para refrigeração artificial, aumentando desnecessariamente o consumo de energia elétrica.

Estudos de conforto térmico que visem analisar e / ou estabelecer condições que avaliem ou ajudem na concepção de um ambiente térmico adequado à Revista Produção Online, Florianópolis, SC, v.12, n. 1, p. 229-247, jan./mar. 2012. 
ocupação humana e às atividades ali exercidas, são importantes para aumentar a eficiência no uso da energia, sobretudo no setor residencial. A energia gasta durante a utilização da edificação representa cerca de 80 a $90 \%$ de toda a energia consumida no ciclo de vida energético da edificação (RAMESH; PRAKASH; SHUKLA, 2010).

Nota-se um aumento no consumo de energia nas edificações em busca de conforto térmico. Huberman e Pearlmutter (2008) afirmam que a demanda mundial por energia tende a aumentar em torno de $71 \%$ entre os anos de 2003 e 2030. Estudos apontam que na França o consumo de energia das edificações tenha crescido 30\% nos últimos 30 anos (KUZNIK et al, 2010).

O conhecimento das características construtivas da edificação e das características climáticas locais permite a pré-avaliação do nível de conforto ambiental e do consumo de energia elétrica que será necessário para o uso da mesma. Muitos softwares que simulam o conforto térmico em edificações levam em consideração características como geometria da construção, dimensões e propriedades térmicas dos materiais nela empregados.

Esta pesquisa tem como objetivo verificar se a escolha dos materiais construtivos influencia na quantidade de energia requerida para a manutenção do estado de conforto térmico utilizando o método Graus-Dia.

\section{REVISÃO BIBLIOGRÁFICA}

\subsection{0 consumo de energia no Brasil}

O Balanço Energético Nacional documenta anualmente pesquisa sobre consumo, produção e comercialização da energia em âmbito nacional. Em março de 2008 foram concluídos levantamentos preliminares que forneceram parâmetros sobre a demanda total de energia no Brasil que, segundo estes estudos, atingiu em 2007, 238,3 milhões de tep (toneladas equivalentes de petróleo). Este número é $5,4 \%$ superior ao verificado em 2006 e correspondeu a $2 \%$ da demanda de energia mundial. (MME, 2008)

O incremento no uso de fontes renováveis (hidráulica, biomassa e outras) é um dos responsáveis pelo aumento da demanda total de energia, indicando um 
crescimento de $7,2 \%$ no uso de energia proveniente dessas fontes. Com isso, a energia renovável passou a compor 45,8\% da Matriz Energética Brasileira.

A Oferta de Energia Elétrica no país em 2007 apresenta um crescimento de $5,2 \%$ em relação ao ano de 2006 . O consumo final de energia elétrica no país atingiu um montante de 411,9 TWh em 2007, sendo que desse total $22,7 \%$ foram destinados ao uso residencial (MME, 2008).

A classe residencial vem apresentando um significativo crescimento percentual em sua participação na matriz elétrica nacional, podendo atingir um terço de toda a energia elétrica consumida no país na próxima década (PROCEL, 2007). A demanda residencial de eletricidade é derivada da demanda por serviços, tais como aquecimento de água, resfriamento, preparação e armazenamento de alimentos e entretenimento, que são realizados pelo uso de aparelhos elétricos. Os determinantes do consumo doméstico de energia elétrica são: o preço da eletricidade, a renda do consumidor, a estrutura residencial, características demográficas e climáticas (GARCEZ e GHIRARDI, 2008).

O Relatório da Pesquisa de Posse de Eletrodomésticos e Hábitos de Uso Classe Residencial ilustra bem este cenário. A pesquisa, realizada em 2005, contemplou 16 estados e o Distrito Federal e contou com a participação de 21 concessionárias de energia elétrica. Seu objetivo foi quantificar a tipologia da posse e obter a declaração de utilização de equipamentos elétricos (CENTRAIS ELÉTRICAS BRASILEIRAS, 2007).

Quanto à participação de eletrodomésticos no consumo de energia elétrica, os aparelhos para condicionamento de ar ocupam a terceira posição no levantamento realizado e são responsáveis por $20,0 \%$ do consumo de energia nas residências (Figura 1). Se analisarmos a posse de eletrodomésticos na região Sul, perceberemos uma diferença da média nacional: aparelhos de condicionamento ambiental aparecem em primeiro lugar no consumo de energia elétrica. Eles são responsáveis por $32 \%$ do consumo nesta região (Figura 2). O estudo mostra também que, na média nacional, $24,5 \%$ dos domicílios avaliados possuem pelo menos um ventilador de teto, sendo que a região Sul apresenta o maior percentual: $34,8 \%$ (Figura 3). 
Figura 1 - Participação dos eletrodomésticos no consumo residencial no Brasil

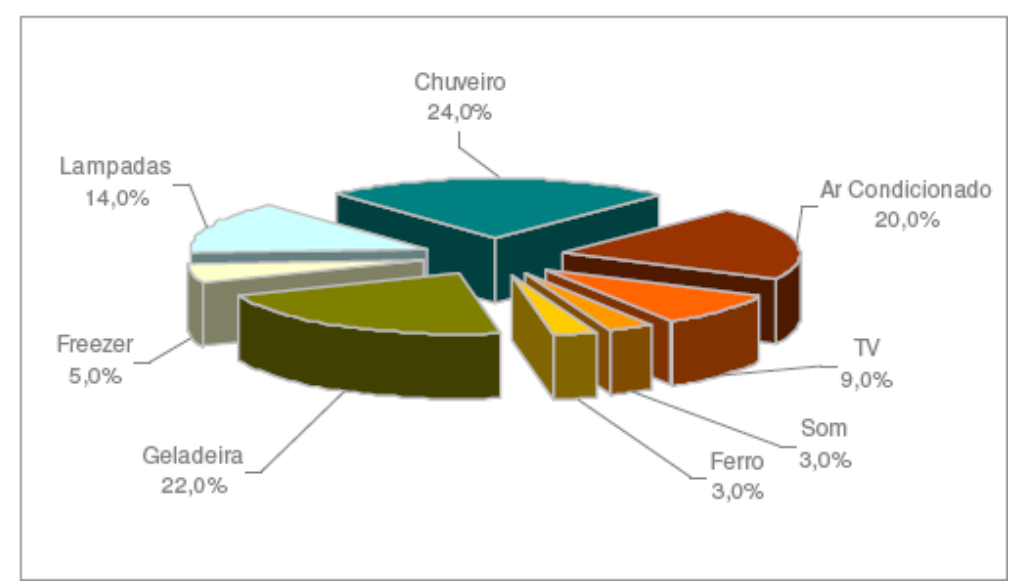

Fonte: (CENTRAIS ELÉTRICAS BRASILEIRAS, 2007)

Figura 2 - Participação dos eletrodomésticos no consumo residencial na região Sul

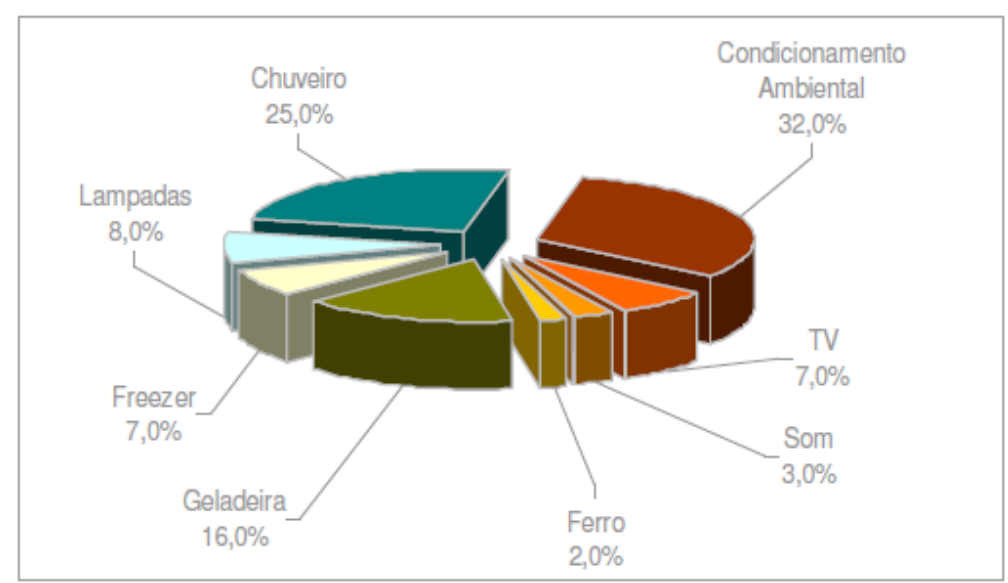

Fonte: (CENTRAIS ELÉTRICAS BRASILEIRAS, 2007)

Figura 3 - Domicílios que possuem pelo menos um ventilador de teto

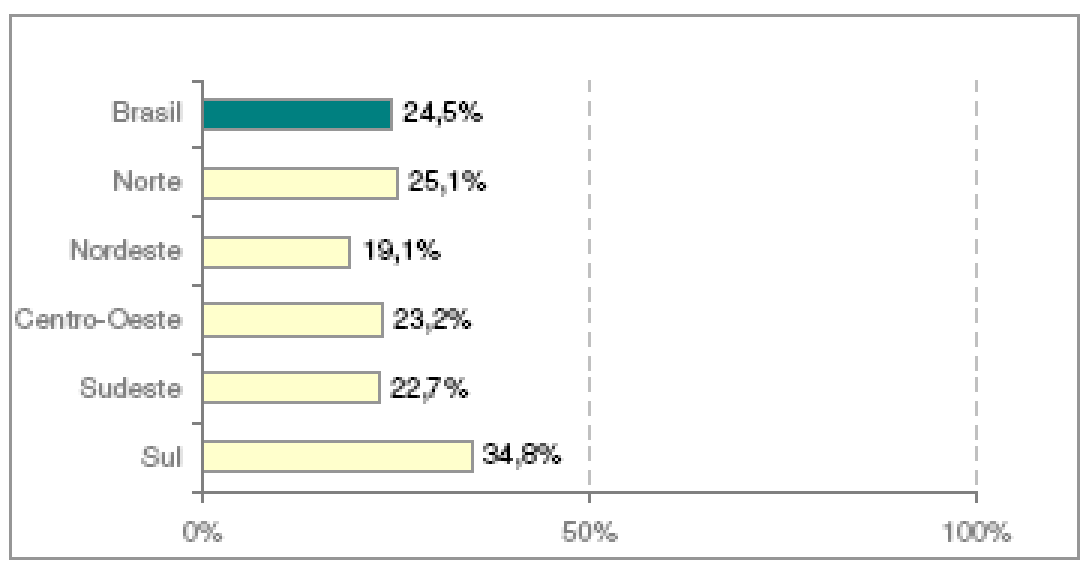

Fonte: (CENTRAIS ELÉTRICAS BRASILEIRAS, 2007) 
Figura 4 - Posse média por eletrodoméstico

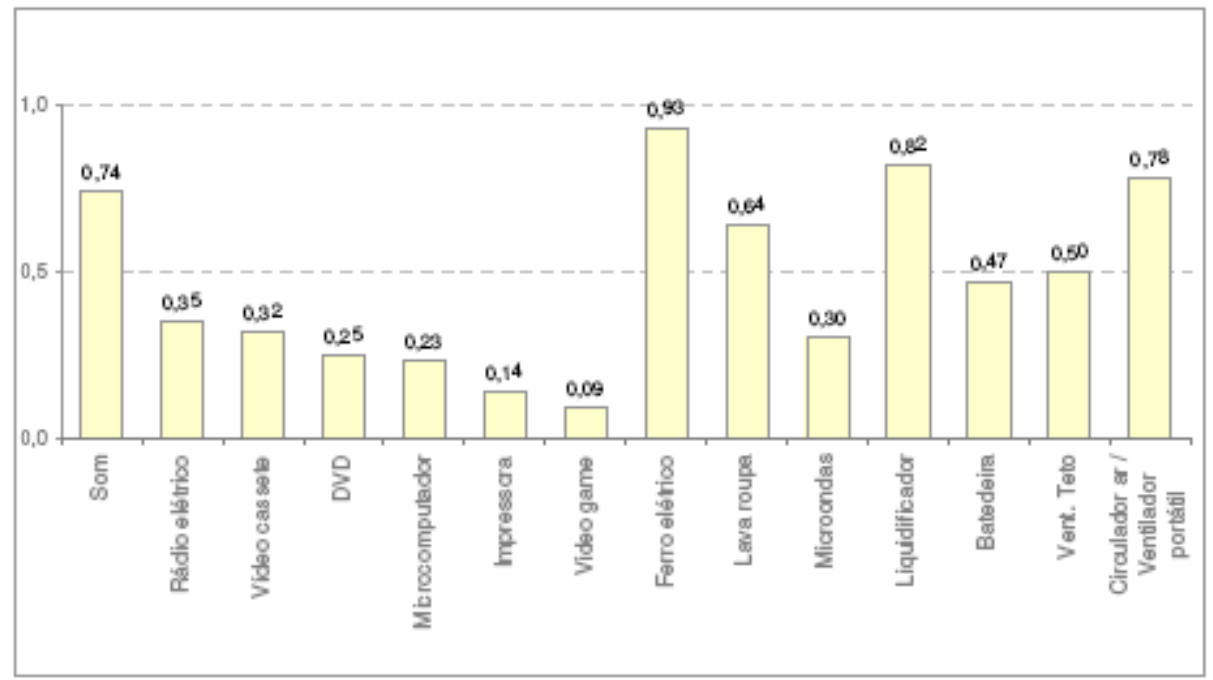

Fonte: (CENTRAIS ELÉTRICAS BRASILEIRAS, 2007)

A Figura 4 apresenta a posse média por eletrodoméstico. Percebe-se posse significativa de ventilador de teto $(0,50)$ e circulador de ar/ventilador portátil $(0,78)$ por residência. Em geral, as Figuras 1 a 4 mostram que a busca por conforto térmico vem mudando o cenário do consumo de energia elétrica no setor residencial, aparelhos como ar condicionado e circulador de ar são responsáveis por grande parte do consumo de energia nas residências.

\subsection{Método Graus - Dia}

Tendo em vista o quadro do consumo de energia elétrica no setor residencial que aponta o crescimento da utilização de aparelhos para conforto térmico, observase a necessidade da utilização de métodos que possam estimar a quantidade de energia elétrica requerida em uma edificação para proporcionar conforto térmico a seus habitantes. Essa estimativa de consumo de energia seria útil para definir a escolha dos materiais mais adequados para a construção.

De acordo com Sailor e Vasireddy (2006), o consumo de energia é composto por duas partes: um consumo base e um consumo variável, que é sensível às variações climáticas. Esse consumo sensível ao clima é normalmente da ordem de $20 \%$ do total da carga energética em residências e edificações.

O conhecimento das características dos materiais construtivos e componentes empregados na construção, assim como das características climáticas 
locais permite a pré-avaliação do consumo de energia elétrica que será necessário para manter determinado nível de conforto térmico durante a utilização da edificação. De acordo com Dombayci (2010), quando se trata da qualidade do conforto térmico nos domicílios, é necessário analisar adequadamente as condições de aquecimento e resfriamento juntamente com os parâmetros meteorológicos.

Segundo Goulart (1995), a aplicação de dados climáticos na construção civil requer um prévio tratamento estatístico ou métodos que transformem uma grande quantidade de registros em ferramentas práticas de trabalho. Os dados obtidos podem ser utilizados em modelos simplificados para análise do consumo de energia de forma rápida, substituindo programas que exigem grande capacidade de memória computacional.

O Método Graus - Dia é uma ferramenta introduzida no final da década de 20 que tem a finalidade de estimar a quantidade de energia requerida para calefação e resfriamento de edificações em diferentes localidades (SAID, 2003). Este método é o mais simples para análise energética e o mais adequado quando o uso da edificação e a eficiência do aparelho de condicionamento de ar são constantes (ASHRAE, 2001).

É baseado no princípio de que as perdas de energia da construção são proporcionais às diferenças de temperatura interna e externa. A energia é adicionada ou retirada da construção quando há perda para manter as condições ideais de conforto no ambiente durante as estações frias e quentes (VENDRAMIN, 2007). Assume-se que a eficiência dos equipamentos destinados a proporcionar conforto térmico não é afetada pelas mudanças externas de temperatura (DOMBAYCI, 2010).

Graus - Dia é um parâmetro climático que pode ser definido como 0 somatório das diferenças de temperatura, quando esta se encontra abaixo de uma temperatura base $\left(T_{b}\right)$. Por exemplo, se a temperatura base adotada é de $18^{\circ} \mathrm{C}$, verifica-se a temperatura média diária $\left(T_{\text {méd }}\right)$ durante todo o ano e quando esta for menor do que $T_{b}$, calcula-se a diferença $\left(T_{b}-T_{\text {méd }}\right)$, somando-se estas diferenças, dia a dia, para todo o ano (GOULART, 1993).

Portanto, para estimar-se a energia requerida para calefação, temos:

$$
H D D=\sum\left(T_{b}-T_{m e ́ d}\right) \quad \text { Equação (1) }
$$

Revista Produção Online, Florianópolis, SC, v.12, n. 1, p. 229-247, jan./mar. 2012. 
A energia requerida para refrigeração pode ser calculada de forma análoga, porém são consideradas as temperaturas que excedem a temperatura base.

$$
C D D=\sum\left(T_{\text {méd }}-T_{b}\right) \quad \text { Equação (2) }
$$

Sendo $H D D$ o número de graus-dia para aquecimento e $C D D$ o número de graus-dia para resfriamento.

Quanto maior o valor de HDD, menores são os valores de temperaturas médias diárias. O oposto ocorre para os valores de CDD (HOR; WATSON; MAJITHIA, 2005).

A temperatura base $\left(T_{b}\right)$ é a temperatura necessária para que haja conforto e varia de um lugar para outro. Muitos autores divergem quanto ao valor a ser adotado para este parâmetro. Segundo Goulart (1993), a Norma Espanhola NBE - CT - 79 recomenda a temperatura base de $15^{\circ} \mathrm{C}$ ao estabelecer os graus - dias anuais para determinar a energia necessária para aquecimento. Em estudos práticos, essa temperatura é adotada como sendo constante. Com base no número de graus-dia, para aquecimento ou resfriamento, e no coeficiente global de perda de calor da edificação é possível estimar a quantidade de energia elétrica necessária para que haja conforto térmico na mesma.

Martinaitis (1998), utilizando dados climáticos da Lituânia, concluiu que o método graus-dia é aplicável na solução de problemas relacionados ao consumo de energia em edificações. Sarak e Satman (2003) estimaram, com sucesso, o potencial de consumo de gás natural destinado à calefação na Turquia, usando o método graus-dia. Kenisarin e Kenisarina (2007) aplicaram o método com esse mesmo objetivo. Christenson, Manz e Gyalistras (2009) avaliaram o impacto do aquecimento climático sobre a demanda de energia em edifícios suíços. Yang, Lam e Tsang (2008), utilizaram o método graus-dia e dados de transferência térmica de materiais para analisar o desempenho energético da envoltória de edifícios em diferentes zonas climáticas na China. Dombayci (2009) calculou os valores de HDD e CDD para diferentes temperaturas base, utilizando dados de temperatura máxima e mínima diária de um período de 21 anos, medidos em 79 cidades da Turquia. Martinaitis, Bieska e Miseviciute (2010) aplicaram o método graus-dia para uma 
análise termodinâmica do uso da energia em edifícios. Papakostas, Mavromatis e Kyriakis (2010) utilizaram o método graus-dia em dados referentes ao período de 1983 a 2002 para verificação da quantidade de energia necessária para aquecimento e resfriamento de edificações.

\section{METODOLOGIA}

Este trabalho teve como base estudo anterior realizado por Pasa e Braghini (2010), em que foram escolhidas quatro residências do Projeto Casa Fácil do CREA e aplicou-se o Método Graus - Dia para as capitais da região Sul do país com o intuito de se estimar a quantidade de energia requerida para que houvesse conforto térmico dos moradores. Desta vez, optou-se por utilizar a residência que se mostrou mais eficiente no estudo anterior como sendo padrão e realizar os testes com as quatro configurações diferentes de materiais construtivos das outras residências para verificar se estes influenciavam no resultado.

\subsection{Residências analisadas}

Para se testar a influência do material construtivo no consumo de energia requerido para conforto térmico, optou-se por se utilizar a residência que apresentou os melhores resultados de eficiência energética. Dentre as quatro residências analisadas no trabalho anterior (modelos 3, 5, 9 e 12), a de número 9 se destacou entre as demais como a mais eficiente energeticamente. Portanto, adotou-se seu projeto arquitetônico como padrão e apenas foram modificados os materiais construtivos. O projeto arquitetônico pode ser visto na Figura 5. 
Figura 5 - Projeto arquitetônico da residência modelo 9

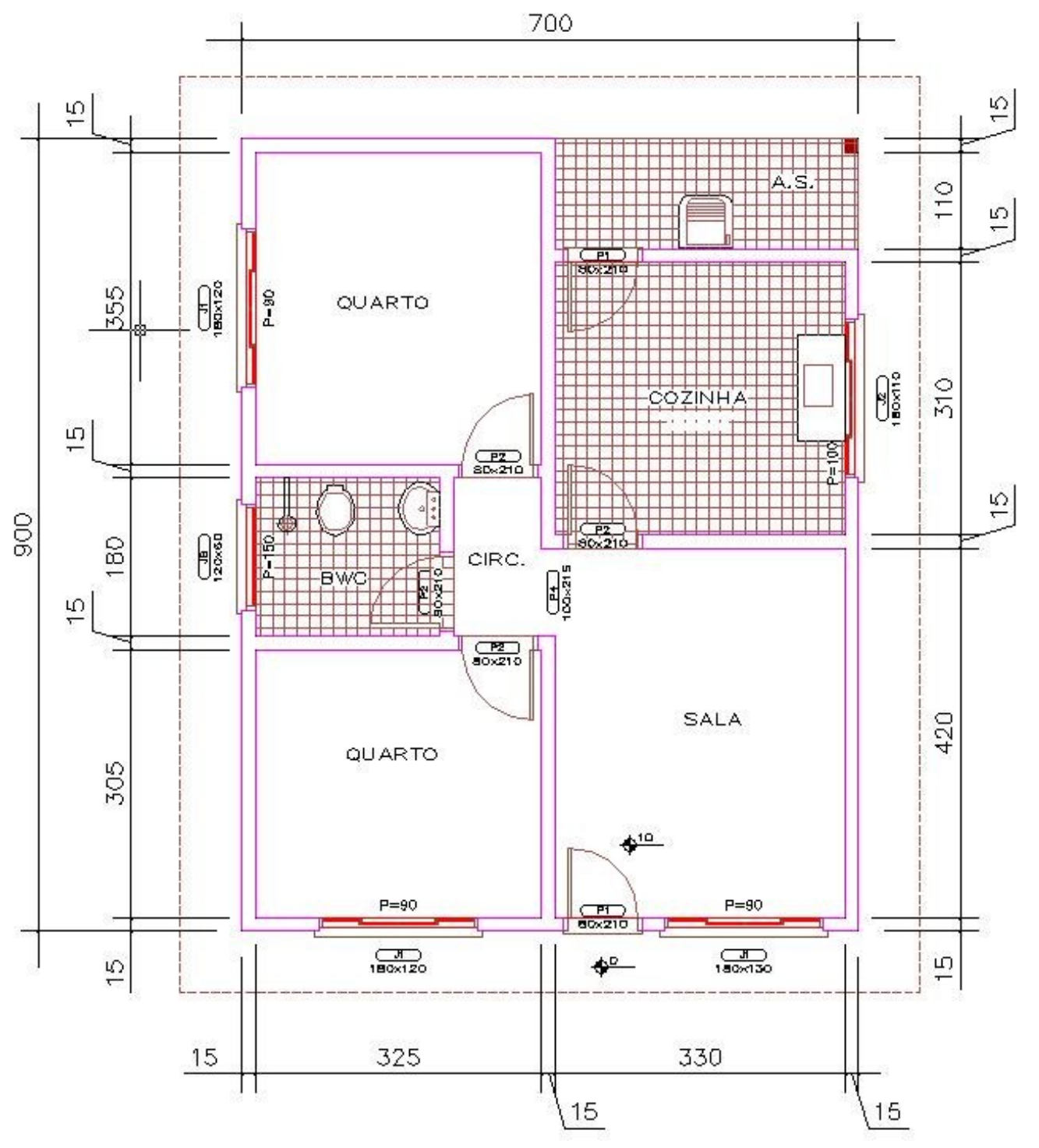

Fonte: CREA (2008)

A residência 9 passou a ser denominada 9 a e as demais foram nomeadas como segue (Quadro 1): 
Quadro 1 - Características construtivas das residências

\begin{tabular}{|c|c|c|}
\hline Residência & Paredes & Cobertura \\
\hline $\operatorname{Res} 9 a$ & $\begin{array}{l}\text { Tijolos maciços, argamassa de assentamento } \\
\text { com } 1,0 \mathrm{~cm} \text {, argamassa de emboço com } 2,5 \mathrm{~cm} \text {. } \\
\text { Espessura da parede: } 15,0 \mathrm{~cm} .\end{array}$ & $\begin{array}{l}\text { Telha de barro com espessura } \\
\text { de } 1,0 \mathrm{~cm} \text {, forro de concreto } \\
\text { com espessura de } 3,0 \mathrm{~cm} \text {. }\end{array}$ \\
\hline $\begin{array}{l}\text { Res 9b } \\
\text { (residência } \\
\text { 3) }\end{array}$ & $\begin{array}{l}\text { Tijolos de } 6 \text { furos circulares, argamassa de } \\
\text { assentamento com } 1,0 \mathrm{~cm} \text {, argamassa de } \\
\text { emboço com } 2,5 \mathrm{~cm} \text {. Espessura da parede: } \\
15,0 \mathrm{~cm} \text {. }\end{array}$ & $\begin{array}{l}\text { Telha de barro com espessura } \\
\text { de } 1,0 \mathrm{~cm} \text { sem forro. }\end{array}$ \\
\hline $\begin{array}{l}\text { Res 9c } \\
\text { (residência } \\
5 \text { ) }\end{array}$ & $\begin{array}{l}\text { Blocos cerâmicos de } 3 \text { furos, argamassa de } \\
\text { assentamento com } 1,0 \mathrm{~cm} \text {, argamassa de } \\
\text { emboço com } 2,5 \mathrm{~cm} \text {. Espessura da parede: } \\
18,0 \mathrm{~cm} \text {. }\end{array}$ & $\begin{array}{l}\text { Telha de barro com espessura } \\
\text { de } 1,0 \mathrm{~cm} \text {, forro de madeira } \\
\text { com espessura de } 1,0 \mathrm{~cm} \text {. }\end{array}$ \\
\hline $\begin{array}{l}\text { Res 9d } \\
\text { (residência } \\
\text { 12) }\end{array}$ & $\begin{array}{l}\text { Tijolos de } 2 \text { furos circulares, argamassa de } \\
\text { assentamento com } 1,0 \mathrm{~cm} \text {, argamassa de } \\
\text { emboço com } 2,5 \mathrm{~cm} \text {. Espessura da parede: } \\
17,5 \mathrm{~cm} \text {. }\end{array}$ & $\begin{array}{l}\text { Telha de barro com espessura } \\
\text { de } 1,0 \mathrm{~cm} \text {, laje de concreto } \\
\text { com espessura de } 20,0 \mathrm{~cm} \text {. }\end{array}$ \\
\hline
\end{tabular}

Os dados de temperatura externa utilizados na elaboração deste trabalho foram os mesmos do trabalho anterior, fornecidos pelo Instituto Nacional de Meteorologia. Para este estudo, optou-se por se analisar os dados da cidade de Curitiba. Foram analisados dados diários de temperatura média do ar medidos no período de janeiro de 1998 a dezembro de 2007.

Manteve-se para este estudo, as temperaturas base obtidas na NBR 6401 que trata de parâmetros básicos de projeto para a instalação de centrais de ar condicionado para conforto térmico. Para o cálculo do número de graus - dia de aquecimento foram adotadas temperaturas bases diferentes no intervalo de $20^{\circ} \mathrm{C}$ a $22^{\circ} \mathrm{C}$. Analogamente para o cálculo do número de graus - dia de resfriamento, foram adotadas temperaturas base no intervalo de $23^{\circ} \mathrm{C}$ a $25^{\circ} \mathrm{C}$.

Os valores de CDD e HDD para a cidade de Curitiba podem ser observados abaixo (Tabela 1): 
Tabela 1 - Valores de CDD e HDD para Curitiba

\begin{tabular}{lccccc}
\hline & $\mathbf{C D D}$ & & \multicolumn{3}{c}{ HDD } \\
$\mathbf{2 3}^{\circ} \mathrm{C}$ & $\mathbf{2 4}^{\circ} \mathrm{C}$ & $\mathbf{2 5}^{\circ} \mathrm{C}$ & $\mathbf{2 0}^{\circ} \mathrm{C}$ & $\mathbf{2 1}^{\circ} \mathrm{C}$ & $\mathbf{2 2}^{\circ} \mathrm{C}$ \\
\hline 24,23 & 8,07 & 3,37 & 976,94 & 1220,45 & 1492,05 \\
\hline
\end{tabular}

Fonte: Autoria própria

\subsection{Coeficiente global de perda de calor}

O coeficiente global de perda de calor depende da arquitetura e materiais construtivos utilizados. Devem ser consideradas as perdas pela envolvente, as perdas localizadas e as perdas pela ventilação. O seu cálculo se dá por:

$$
L=\sum U \cdot A+I \cdot(\delta \cdot C p)_{A R} \cdot \frac{V}{3,6} \quad \text { Equação (4) }
$$

Onde:

$U$ é o coeficiente global de transferência de calor;

$A$ é a área dos ambientes;

I é a taxa de troca de ar

$V$ é o volume interno da construção;

$\delta C p$ é a capacidade térmica volumétrica do ar.

Como o projeto arquitetônico é o mesmo para todas as residências, as áreas e volumes são os mesmo para todas (Tabela 2):

Tabela 2- Quantificação de áreas e volumes das residências

\begin{tabular}{lccccc}
\hline Residência & \multicolumn{4}{c}{ Área $\left(m^{2}\right)$} & Volume $\left(m^{3}\right)$ \\
& Paredes & Cobertura & Aberturas & Piso & \\
\hline 9a, 9b, 9c, 9d & 77,14 & 63,00 & 9,36 & 63,00 & 145,74 \\
\hline
\end{tabular}

Fonte: Autoria própria

Os valores de $U$ foram obtidos no Projeto de Norma 02:135.07-001/3: Desempenho térmico de edificações, com exceção dos valores para aberturas e pisos, que não estavam contemplados no referido Projeto de Norma. Estes foram os 
mesmos utilizados por Durmayaz (2000). A Tabela 3 traz a relação dos valores utilizados.

Tabela 3 - Valores de U conforme materiais construtivos empregados

\begin{tabular}{lllll}
\hline Residência & $\begin{array}{c}U\left(W / m^{2} \cdot K\right) \\
\text { Paredes }\end{array}$ & Cobertura & Aberturas & Piso \\
\hline Res 9a & 3,13 & 2,24 & 5,91 & 0,12 \\
Res 9b & 2,28 & 4,55 & 5,91 & 0,12 \\
Res 9c & 2,43 & 2,00 & 5,91 & 0,12 \\
Res 9d & 2,43 & 1,84 & 5,91 & 0,12 \\
\hline
\end{tabular}

Fonte: Autoria própria

A capacidade térmica volumétrica do ar considerada foi de $1,2 \mathrm{k} \cdot \mathrm{J} / \mathrm{m}^{3} \cdot \mathrm{K}$, o mesmo utilizado por Durmayaz (2000), e a taxa de troca de ar foi de 1 troca/hora. A Tabela 4 mostra o coeficiente global de perda de calor para cada residência.

\begin{tabular}{|c|c|}
\hline Residência & $L(W / K)$ \\
\hline Res 9a & 332,85 \\
\hline Res 9b & 573,99 \\
\hline Res 9c & 424,91 \\
\hline Res 9d & 414,83 \\
\hline
\end{tabular}

Fonte: Autoria própria

\subsection{Cálculo do consumo anual de energia}

Após a determinação dos parâmetros anteriores, foi avaliado o desempenho energético das edificações.

Utilizando os valores de HDD e CDD, calculou-se o consumo anual médio de energia para resfriamento $\left(Q_{c}\right)$ e aquecimento $\left(Q_{h}\right)$ através das seguintes equações:

$$
Q_{c}=C D D \cdot L \cdot \frac{24}{1000} \quad \text { Equação }(5)
$$




$$
Q_{h}=H D D \cdot L \cdot \frac{24}{1000} \quad \text { Equação (6) }
$$

Onde $Q_{c}$ e $Q_{h}$ fornecem valores em $\mathrm{kWh} /$ ano .

\section{RESULTADOS E DISCUSSÕES}

\subsection{Energia requerida para resfriamento}

Utilizando-se os dados de CDD da Tabela 1 e os valores do coeficiente global de perda de calor calculados para cada residência, pode-se obter através da equação (5) a quantidade de energia requerida para resfriamento $\left(Q_{c}\right)$ na cidade de Curitiba. O Gráfico 1 mostra os resultados considerando-se o intervalo estabelecido anteriormente para a temperatura base.

Gráfico 1 - Quantidade de energia requerida para resfriamento $(k W h / a n o)$

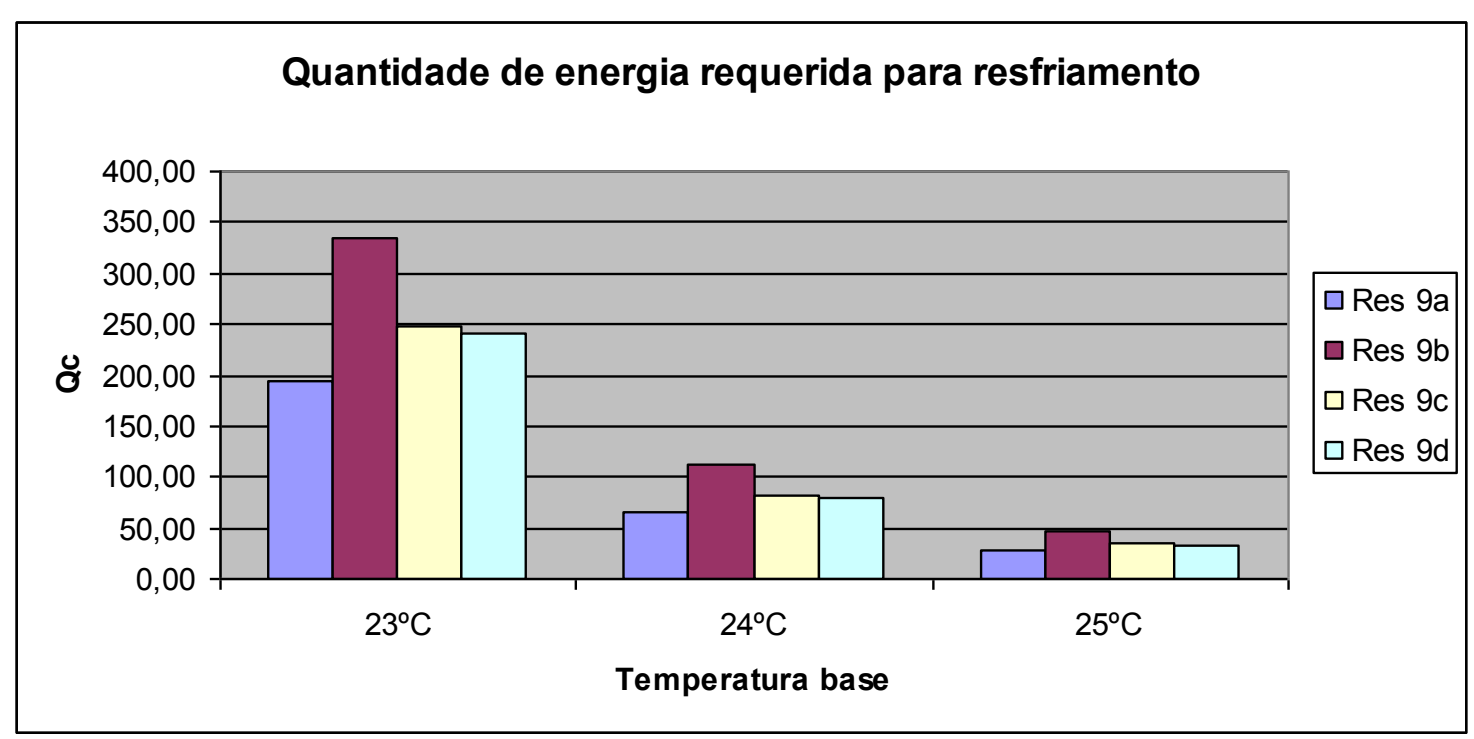

Fonte: Autoria própria

Percebe-se que, para qualquer uma das temperaturas adotadas, a residência 9a é a que apresenta os menores valores de energia para resfriamento. Nota-se também a influência do clima nos resultados: quanto mais a temperatura base se aproxima de $25^{\circ} \mathrm{C}$, menores são os valores de energia requerida para resfriamento. Isso mostra que, no período analisado, a temperatura média da cidade não foi muito 
superior à temperatura base estabelecida. Como Curitiba, tradicionalmente, não apresenta temperaturas muito elevadas, não há a necessidade de grande quantidade de energia para resfriamento em suas residências.

A residência $9 \mathrm{~b}$ apresentou os maiores valores de energia requerida para resfriamento. Se observarmos os parâmetros construtivos estabelecidos anteriormente, esta residência foi a única em que não houve a previsão de forro na cobertura. E este elemento também apresentou o maior coeficiente global de transferência de calor $(U)$ dentre todas as residências.

Comparando-se os valores obtidos no estudo anterior (Tabela 6), observa-se que há diferenças nas quantidades de energia requeridas. Como o material construtivo empregado é o mesmo, conclui-se que esta diferença se deve ao projeto arquitetônico. Este influência na área dos ambientes e volume interno da edificação, parâmetros que, de acordo com a equação 4 , influenciam o coeficiente global de perda de calor. Como se tratam de casas populares, a área total de cada uma não apresenta grande variação. Isto explica o pequeno incremento nos valores de $Q_{c}$, ressaltando mais uma vez a importância da correta escolha dos materiais construtivos para cada região.

Tabela 6 - Quantidade de energia requerida para resfriamento $(\mathrm{kWh} / \mathrm{ano})$ comparando com estudo anterior

\begin{tabular}{cccccccc}
\hline \multirow{2}{*}{$T_{b}$} & & \multicolumn{7}{c}{$Q_{c}$} \\
& $\operatorname{Res} \mathbf{9 a}$ & $\operatorname{Res} \mathbf{3}$ & $\operatorname{Res} \mathbf{9 b}$ & $\operatorname{Res} \mathbf{5}$ & $\operatorname{Res} 9 \mathbf{c}$ & $\operatorname{Res} \mathbf{1 2}$ & $\operatorname{Res} \mathbf{9 d}$ \\
\hline $23^{\circ} \mathrm{C}$ & 193,59 & 300,35 & 333,84 & 261,76 & 247,13 & 240,98 & 241,27 \\
$24^{\circ} \mathrm{C}$ & 64,48 & 100,21 & 111,20 & 87,19 & 82,32 & 80,27 & 80,36 \\
$25^{\circ} \mathrm{C}$ & 26,94 & 41,86 & 46,45 & 36,42 & 34,39 & 33,53 & 33,57 \\
\hline
\end{tabular}

Fonte: Autoria própria

\subsubsection{Energia requerida para aquecimento}

Analogamente ao cálculo de $Q_{c}$, a energia requerida para aquecimento $\left(Q_{h}\right)$ foi calculada através da equação (6) utilizando-se os valores de HDD e de coeficiente global de perda de calor calculados. O Gráfico 2 mostra os resultados obtidos para $Q_{h}$. 
Gráfico 2 - Quantidade de energia requerida para aquecimento $(\mathrm{kWh} / \mathrm{ano})$

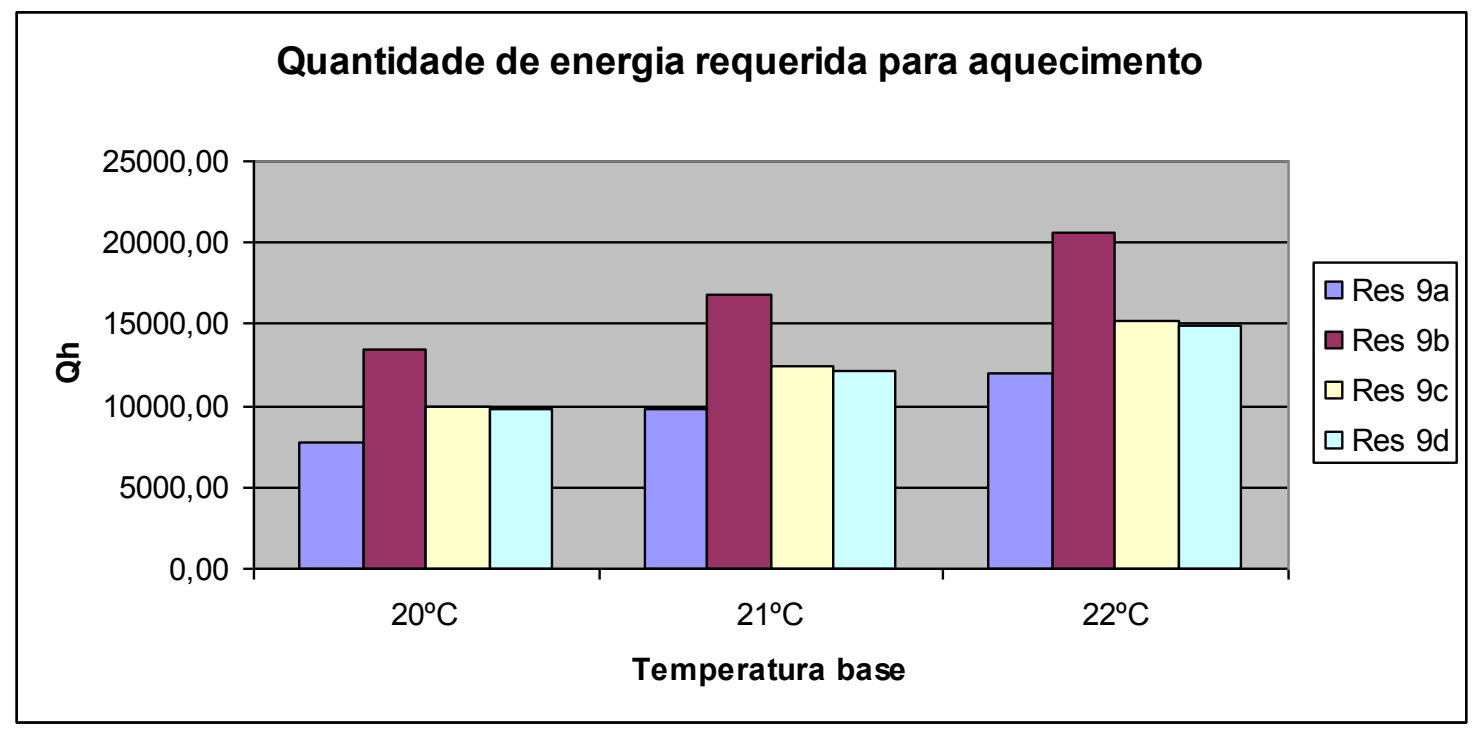

Fonte: Autoria própria

Neste caso, nota-se que os valores para a quantidade de energia para aquecimento são mais elevados do que os apresentados no item anterior. Isto se deve, novamente, pela influência do clima local. A cidade apresenta médias de temperatura muito baixas nas estações frias, portanto há maiores diferenças entre a temperatura média do período analisado e as temperaturas base estabelecidas. Os valores de HDD serão maiores e por consequência a quantidade de energia para aquecimento também.

Percebe-se, mais uma vez, que a residência 9a apresenta os menores valores de energia para aquecimento. As residências $9 c$ e $9 d$ apresentam valores bem próximos e não muito maiores do que a residência 9a. Talvez, pequenas alterações em seus materiais construtivos as tornariam mais eficientes energeticamente. A residência 9b, novamente, apresenta os maiores valores de energia para aquecimento.

Quando comparado com o estudo anterior, a quantidade de energia requerida para aquecimento também apresentou algumas diferenças de valores (Tabela 7). Percebe-se que os modelos adotados no estudo atual, necessitariam de maior quantidade de energia, mais uma vez influenciado pelo projeto arquitetônico das edificações. 
Tabela 7 - Quantidade de energia requerida para aquecimento $(\mathrm{kWh} / \mathrm{ano})$ comparando com estudo anterior

\begin{tabular}{cccccccc}
\hline \multirow{2}{*}{$T_{b}$} & & & \multicolumn{9}{c}{$Q_{h}$} \\
& Res 9a & $\operatorname{Res} 3$ & Res 9b & Res 5 & Res 9c & Res 12 & Res 9d \\
\hline $20^{\circ} \mathrm{C}$ & 7804,22 & 12128,30 & 13458,07 & 10552,12 & 9962,67 & 9714,62 & 9726,32 \\
$21^{\circ} \mathrm{C}$ & 9749,41 & 15151,26 & 16812,48 & 13182,23 & 12445,85 & 12135,98 & 12150,60 \\
$22^{\circ} \mathrm{C}$ & 11919,06 & 18523,05 & 20553,95 & 16115,82 & 12150,60 & 14836,74 & 14854,61 \\
\hline
\end{tabular}

Fonte: Autoria própria

\section{CONCLUSÕES}

Este estudo teve o intuito de, com base em pesquisa anterior, comparar a influência dos materiais construtivos na eficiência energética de edificações unifamiliares para a cidade de Curitiba através da utilização do Método Graus - Dia.

Como a cidade em questão apresenta temperaturas amenas durante o ano, constatou-se que a quantidade de energia requerida para resfriamento é muito pequena se comparada à quantidade de energia requerida para aquecimento. Isto mostra que o projeto de residências deve se iniciar pelo estudo adequado do clima local e escolha dos materiais mais adequados para a região antes da idealização do projeto.

Os resultados mostram que a residência intitulada 9a seria a mais eficiente com relação à quantidade de energia necessária para resfriamento quanto para aquecimento. Porém, percebeu-se que as residências 9c e 9d apresentaram valores razoáveis com relação à quantidade de energia para aquecimento, pequenas modificações em seus materiais construtivos poderiam ser uma boa alternativa para melhorar seu desempenho. Nas duas situações, a residência 9b apresentou o pior desempenho energético. Durante a configuração dos materiais construtivos para cada residência, esta foi a única em que não houve a previsão de forro na cobertura e este elemento apresentou os maiores valores de coeficiente global de transferência de calor $(U)$. Esta pode ser uma das razões para seus valores mais elevados. Como o projeto arquitetônico adotado foi o mesmo para todas as residências, fica nítida a influência que os materiais construtivos empregados exercem sobre o consumo de energia elétrica para proporcionar conforto térmico a seus ocupantes. 
Deve-se levar em consideração que para esta simulação, considerou-se que o aparelho destinado a proporcionar conforto térmico estaria ligado 24 horas por dia durante o ano todo. Assume-se que a eficiência dos equipamentos destinados a proporcionar conforto térmico não é afetada pelas mudanças externas de temperatura (DOMBAYCI, 2010).

\section{AGRADECIMENTOS}

Agradecemos ao Instituo Nacional de Meteorologia por ceder os dados de temperatura utilizados neste estudo.

\section{REFERÊNCIAS}

ASSOCIAÇÃO BRASILEIRA DE NORMAS TÉCNICAS. NBR 6401: Instalações centrais de ar condicionado para conforto - Parâmetros básicos de projeto. Rio de Janeiro: ABNT,1980.

Projeto 02:135.07-001/3: Desempenho térmico de edificações - Parte 3: Zoneamento bioclimático brasileiro e diretrizes construtivas para habitações unifamiliares de interesse social. Rio de Janeiro: ABNT, 2003.

CENTRAIS ELÉTRICAS BRASILEIRAS. Pesquisa de posse de equipamentos e hábitos de uso, ano base 2005: classe residencial. Rio de Janeiro: ELETROBRÁS; PROCEL, 2007.

CHRISTENSON, M.; MANZ, H.; GYALISTRAS, D. Climate warming impact on degree-days and building energy demand in Switzerland. Energy, Conversion and Management, n. 47, p. 671 - 686, 2006.

CONSELHO REGIONAL DE ENGENHARIA ARQUITETURA E AGRONOMIA CREA. Programa Casa Fácil. Disponível em: <http://www.creapr.org.br>. Acesso em: 01 jul. 2008.

DOMBAYCI, Ö. A. Degree-days maps of Turkey for various base temperatures. Energy, n. 34, p. 1807 - 1812, 2009.

. The prediction of heating energy consumption in a model house by using

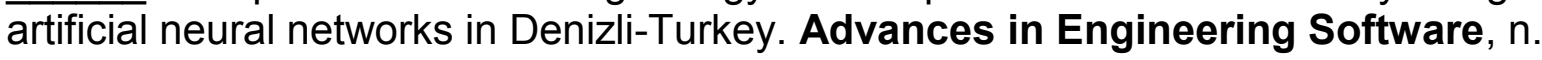
41 , p. $141-147,2010$.

DURMAYAZ, A.; KADIOGLU, M.; SEM, Z. An application of the degree-hours method to estimate the residential heating energy requirement and fuel consumption in Istanbul. Energy, n. 25, p. 1245 - 1256, 2000. 
GARCEZ, E. W.; GHIRARDI, A. G. Elasticidades da demanda residencial de energia elétrica. In: ENCONTRO NACIONAL DE ECONOMIA, 31., 2003, Porto Seguro.

Anais eletrônicos... Porto Seguro: ANPEC, 2003. Disponível em:

<http://www.anpec.org.br/encontro2003/artigos/D34.pdf>. Acesso em: 30 mar. 2008.

GOULART, S. V. G. Dados climáticos para avaliação de desempenho térmico de edificações em Florianópolis. 1993. Dissertação (Mestrado em Engenharia Civil) Universidade Federal de Santa Catarina.

GOULART, S. V. G.; LAMBERTS, R. Dados climáticos para uso em cálculos simplificados de consumo de energia. Conforto no ambiente construído, III Encontro Nacional - I Encontro Latino - Americano, 1995.

HUBERMAN, N.; PEARLMUTTER, D. A life - cycle energy analysis of building materials in the Negev desert. Energy and Buildings, n. 40, p. 837 - 848, 2008.

HOR, C. L.; WATSON, S. J.; MAJITHIA, S. Analyzing the impact of weather variables on monthly electricity demand. IEEE Transactions on Power Systems, n. 4, p. 2078 - 2085, 2005.

INSTITUTO NACIONAL DE METEOROLOGIA. Dados climáticos das capitais brasileiras (1998 - 2007). Brasília, 2008. 1 CD-ROM.

KENISARIN, M.; KENISARINA, K. Energy saving potential in the residential sector of Uzbekistan. Energy, n. 32, p. 1319 - 1325, 2007.

KUZNIK, F. et al. A review on phase change materials integrated in building walls. Renewable and Sustainable Energy Reviews, 2010, doi:10.1016/j.rser.2010.08.019.

MARTINAITIS V. Analytic calculation of degree-day for the regulated heating season. Energy and Buildings, n. 28, p. 185-189, Fev. 1998.

MARTINAITIS, V.; BIEKSA, D.; MISEVICIUTE, V. Degree-days for exergy analysis of buildings. Energy and Buildings, n. 42, p. 1063 - 1069, 2010.

MINISTÉRIO DE MINAS E ENERGIA - MME. Resenha Energética Brasileira: exercício de 2007. Brasília, 2008. Disponível em: <http://www.mme.gov.br>. Acesso em jul. 2008.

PAPAKOSTAS, K.; MAVROMATIS, T.; KYRIAKIS, N. Impact of the temperature rise on the energy consumption for heating and cooling in residential buildings of Greece. Renewable Energy, n. 35, p. 1376 - 1379, 2010.

PASA, C. C. M. U.; BRAGHINI, A. Aplicação do método graus - dia para avaliação do desempenho energético de edificações unifamiliares. In: ENCONTRO NACIONAL DE ENGENHARIA DE PRODUÇÃO, 30., 2010, São Carlos. Anais eletrônicos... São Carlos: ABEPRO, 2010. Disponível em:

<http://www.abepro.org.br/biblioteca/enegep2010_TN_STO_121_786_15236.pdf>. Acesso em: 01 nov. 2010. 
RAMESH, T.; PRAKASH, R.; SHUKLA, K. K. Life cycle energy analysis of buildings: An overview. Energy and Buildings, n. 42, p. 1592 - 1600, 2010.

SAID, S. A. M.; HABIB, M. A.; IQBAL, M. O. Database for building prediction in Saudi Arabia. Energy Conversion \& Management, n. 44, p. 191 - 201, 2003.

SAILOR, D. J.; VASIREDDY, C. Correcting aggregate energy consumption data to account for variability in local weather. Environmental Modelling \& Software, n. 21, p. $733-738,2006$.

SARAK H.; SATMAN A. The degree-day method to estimate the residential heating natural gas consumption in Turkey: a case study. Energy, n. 28, p. 929-939, 2003.

VENDRAMIN, A. L. Método graus - dia para avaliação do desempenho térmico de uma edificação unifamiliar em diferentes condições climáticas. 2007.

Dissertação (Mestrado em Engenharia Agrícola) - Universidade Estadual do Oeste do Paraná.

YANG, L.; LAM, J. C.; TSANG, C. L. Energy performance of buildings envelopes in different climate zones in China. Applied Energy, n. 85, p. $800-817,2008$.

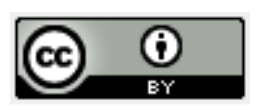

Artigo recebido em 23/11/2010 e aceito para publicação em 20/12/2011. 